\title{
Medicolegal Significance of Using Smell of Liquor as an Indicator of Alcohol Consumption
}

\author{
Tikiri Bandara KM Gunathilake ${ }^{1 *}$, Muditha Vidanapathirana ${ }^{2}$ \\ ${ }^{1}$ Office of the Judicial Medical Officer, Base Hospital, Awissawella, Sri Lanka, \\ ${ }^{2}$ Depratment of Forensic Medicine, Faculty of Medical Sciences, University of Sri Jayewardenepura, Sri Lanka
}

\begin{abstract}
Introduction: Alcohol is odour-less and the smell of liquor originates due to additives. Currently, some liquors are also odour-less and chasers also mask the smell. However, the Medical Officers are expected to identify the odours of liquors for medico-legal purposes and an error in the opinion on smelling of liquor may affect medical officer's career. This research was performed to study the ability to detect the smell of liquor of alcoholic and non-alcoholic beverages by the health personnel.

Methods: A cross-sectional descriptive study was performed in a tertiary care hospital with 100 randomly selected doctors, medical students, nurses and minor employees, 25 of each group. Non-named four alcoholic samples (beer, gal arrack, Lemon Gin and pure alcohol) and four non-alcoholic samples (ginger, garlic, lemon and water) were kept in eight rooms. Participants detected the sample and selected the options in the questionnaire.

Results: 'Beer', 'gal arrack' and 'pure alcohols' were correctly identified by $94 \%, 68 \%$ and $89 \%$ respectively. However, irrespective of high concentration, 'Lemon Gin' was detected by $40 \%$. When detection of smell of all liquors was compared with sex and the occupation, the differences were not significant ( $p>0.05)$. When detection of liquor smell was compared with the age groups, the difference was not significant for beer and gal arrack ( $>0.05)$ but significant for Lemon Gin $(\mathrm{p}=0.045<0.05)$.

Conclusions: The detection of the smell of liquor is affected by the familiarity, masking effects and age of health personnel. Therefore, medical officers tend to miss the diagnosis of liquor smell and lead to legal and personal consequences. In the absence of special training on detection of smell of liquor, these consequences could not be justified. The smell of liquor is subjective and cannot be reproduced. Therefore, for confirmation, we recommend introducing scientific methods such as blood analysis or non-invasive urine, saliva or sweat analysis. Our data may help to convince medico-legal policymakers to adopt a change.
\end{abstract}

Keywords: Alcohol, detection, lemon, liquor, smell,

Received: 02 May 2019, Revised version accepted: 20 June 2019, Published: 30 June 2018. *Corresponding author: Gunathilake KMTB, \Email: Tikiriii_bandara@yahoo.com, (D) https://orcid.org/0000-0002-8485-4550

Cite this article as: Gunathilake KMTB, Vidanapathirana M. Medicolegal Significance of Using Smell of Liquor as an Indicator of Alcohol Consumption. Medico-Legal Journal of Sri Lanka, 2019;7(1): 8-14. DOI: http://doi.org/10.4038/mljsl.v7i1.7388

Copyright: @ 2019 with the Medico-legal Journal of Sri Lanka.

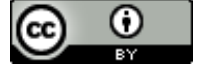

This is an open-access article distributed under the terms of the unrestricted use, distribution and reproduction in any medium provided the original author and source are credited.

\section{Introduction}

Alcohol-related issues cause serious medicolegal impacts and problems for society. Even in Buddhist history, an elephant intoxicated with 500 pots of toddy was sent to attack the Lord Buddha. ${ }^{[1]}$ Today, many such incidents are taken place at home, road, public places and workplaces that warrants medicolegal investigations. Other than non-communicable diseases, liquor causes significant social and legal issues and some end up in fatalities.
In Sri Lanka, the alcohol-related offences that are covered by law include; drunken driving, alcoholrelated offences towards children, public nuisance and government workplace related offences etc. Clinicians also have to document their observations on the smell of liquor or Under the influence of liquor (UIL) in the Bedhead ticket (BHT). Further, one of the basic medicolegal duties of a government medical officer is to examine persons produced by police alleging 
offences committed under the influence of liquor. Then, he/she should give an opinion on whether the person has consumed liquor, under influence of liquor, fitness for detention and most importantly to exclude the possible differential diagnosis. During this task, he/she has to rely on the facts, though some are subjective, such as the smell of liquor.

According to motor traffic Act, a person cannot be in charge of a vehicle once he had consumed alcohol. ${ }^{[2]}$ In practical situations, deciding whether the person has consumed alcohol or not is decided by the presence or absence of the smell of liquor. There is a cage to fill in the Medico-legal examination form (MLEF) and Medico-legal report (MLR) whether the smell of liquor is present or not.

In fact, alcohol is odour-less, colourless and tasteless, but the unique smell of liquor originates due to additives and congeners. ${ }^{[3,4]}$ According to the Sri Lankan laws, a medical officer who examines a person alleged with an offence related to under influence of liquor has to give an opinion on the smell of liquor. Now, there are many liquor brands available in the market, however, some of them are foreign liquors, and have not even been seen by the medical officers and some are odour-less. Further, there is no such special training in the undergraduate or postgraduate training period for detection of smell of liquor. Further, adding of chasers such as coke, soda, lemon etc, may alter or mask the smell of the liquor and may adversely alter the opinion on the smell of liquor and may affect medicolegal opinions. Therefore, it is unfair to expect to identify the whole range of different odours of liquors by medical officers and to give opinions. Further, even a minimum error in the medicolegal opinion may adversely affect not only the victims and offenders but also the careers of the medical officers.

Therefore, the following research was performed to study the ability to detect the smell of liquor of different alcoholic beverages and to differentiate them from the non-alcoholic beverages by the health personnel those who manage the patients under influence of liquor in hospitals.

\section{Methods}

A cross-sectional descriptive study was conducted in a hospital in Sabaragamuwa province during the months of August, September and October 2018 with the participation of 100 personnel from selected groups of health personnel who managed alcoholic patients.

A randomly selected sample of different categories of health care personnel; doctors, medical undergraduates, nurses and other minor employees of the hospital -25 from each category participated in this study. Those who had allergy to different smells, who had ENT problems or defects in smelling and pregnant females were excluded.

After obtaining informed written consent from each participant, they were given a self-administered data collection form and were requested to indicate demographic data such age, sex, occupation etc., history of use of alcoholic beverages, and whether afflicted with any ENT condition that affects smelling. Eight small dark bottles each labelled as A, B, C, D, E, F, G and H, containing samples of different types of alcoholic liquids (4 bottles) and samples of nonalcoholic liquids (4 bottles) were kept each in a separate room.

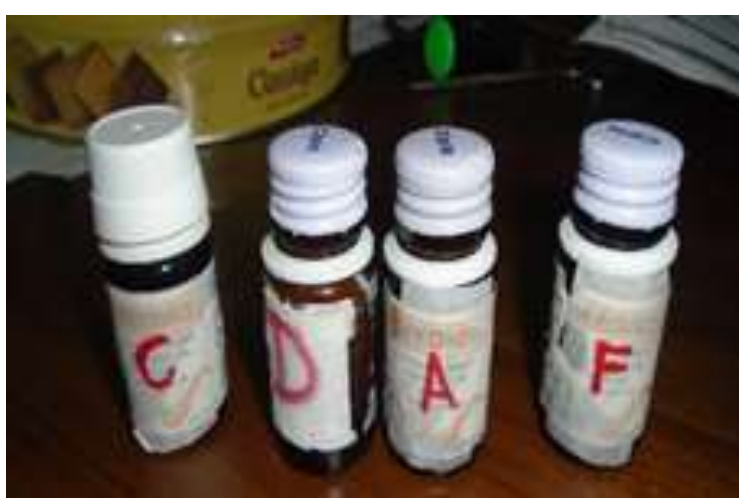

Figure 01: Samples were labelled as A, B, C, D, E, F, $\mathrm{G}$ and $\mathrm{H}$

The alcoholic and non-alcoholic liquids in the bottles were as follows: The four (04) alcoholic samples were (i) Lemon Gin (labelled as A), (ii) Pure alcohol (95\% isopropyl alcohol/surgical spirit) (labelled as B), (iii) Beer (labelled as C) and (iv) Gal Arrack(labelled as E). Of them, three were liquors; Beers, Gal arrack and Lemon Gin. The four (04) non-alcoholic samples were (i) Lemon (labelled as D), (ii) Garlic (labelled as F), (iii) Water (labelled as G) and (iv) Ginger (labelled as $\mathrm{H})$.

The mouth of each bottle was closed with a tightly fitting lid. Participants were sent to each room one at a time. The content of each bottle was not known to the participants. Participants were requested to dip a cotton swab into each bottle and feel the smell of the soaked swab by sniffing and indicate the identity in the liquid of each bottle by selecting the options available in the questionnaire. For this purpose, a list of 12 possible names of fluids was provided in the questionnaire. Among the listed 12 liquids, 6 correct names of smells (liquor, pure alcohol, lemon, ginger, garlic, water) and of them, some were 
mentioned more than once. One name of other fluids (perfume) was also there in the list. (See Annexure $01)$.

Pure alcohol does not have a smell except for its irritant and spirituous smell. However, the other alcoholic beverages have a liquor smell depending on their basic ingredients and additives. The alcohol content of Beer was $4.8 \%$, in Gal arrack $33.5 \%$, in Lemon Gin 39\% and in pure alcohol 95\%. IBM-SPSS statistical package was used for univariate and multivariate analysis of the data. The approval was obtained from the hospital research ethics committee to conduct this study.

\section{Results}

Out of 100 participants $63 \%(n=63)$ were females. The ages ranged from 20 to 58 years and the majority (39\%) belonged to 30-39 years of age. Based on the consumption of alcohol, the majority $(74 \%, n=74)$ were non-alcoholics, $15 \%(\mathrm{n}=15)$ occasional drinkers and the remaining $11 \%(\mathrm{n}=11)$ were habitual drinkers. None of the participants had ENT disorders or problems in the smell.

Out of 04 alcohol samples, beer was correctly identified as the smell of liquor by $94 \%(n=94)$ and the remaining $6 \%(\mathrm{n}=06)$ wrongly identified it as pure alcohol. Gal arrack was detected as the smell of liquor by $68 \%(n=68)$, and $9 \%$ and $10 \%$ wrongly identified it as pure alcohol and water consecutively. However, Lemon Gin was correctly detected as the smell of liquor only by $40 \%(\mathrm{n}=40)$, and $30 \%$ and $22 \%$ wrongly identified it as lemon and perfume consecutively. Pure alcohol was detected by $89 \% \quad(n=89)$ and the remaining $6 \%$ and $5 \%$ wrongly identified as perfume and lemon consecutively. The correct detection of alcoholic and non-alcoholic samples by all the participants is shown in Table 01 .

Table 01: Correct detection of all alcoholic and non-alcoholic fluids by all participants

\begin{tabular}{llllll}
\hline Sample & $\begin{array}{l}\text { Doctors } \\
\mathbf{n}(\boldsymbol{\%})\end{array}$ & $\begin{array}{l}\text { Nurses } \\
\mathbf{n}(\boldsymbol{\%})\end{array}$ & $\begin{array}{l}\text { Workers } \\
\mathbf{n}(\boldsymbol{\%})\end{array}$ & $\begin{array}{l}\text { Stud } \\
\mathbf{n}(\boldsymbol{\%})\end{array}$ & $\begin{array}{l}\text { Total } \\
\mathbf{n}(\boldsymbol{\%})\end{array}$ \\
\hline C (Beer) & $24(96)$ & $24(96)$ & $22(88)$ & $24(96)$ & $\mathbf{9 4}(\mathbf{9 4})$ \\
B (Pure alcohol) & $21(84)$ & $24(96)$ & $24(96)$ & $20(80)$ & $\mathbf{8 9}(\mathbf{8 9})$ \\
E (Gal Arrack) & $18(72)$ & $17(68)$ & $17(68)$ & $16(64)$ & $\mathbf{6 8}(\mathbf{6 8})$ \\
A (Lemon Gin) & $10(40)$ & $09(36)$ & $11(44)$ & $10(40)$ & $\mathbf{4 0}(\mathbf{4 0})$ \\
& & & & & \\
F (Garlic) & $25(100)$ & $20(80)$ & $25(100)$ & $21(84)$ & $\mathbf{9 1}(\mathbf{9 1})$ \\
H (Ginger) & $23(92)$ & $20(80)$ & $20(80)$ & $18(72)$ & $\mathbf{8 1}(\mathbf{8 1})$ \\
D (Lemon) & $21(84)$ & $18(72)$ & $18(72)$ & $21(84)$ & $\mathbf{7 8}(\mathbf{7 8})$ \\
G (Water) & $24(96)$ & $22(88)$ & $21(84)$ & $17(68)$ & $\mathbf{8 4}(\mathbf{8 4})$ \\
& & & & & \\
\hline
\end{tabular}

A comparison of the detection of the alcoholic samples such as Beer, Gal arrack, Lemon Gin and pure alcohol is shown in Fig. 02.

Detection of alcohol samples

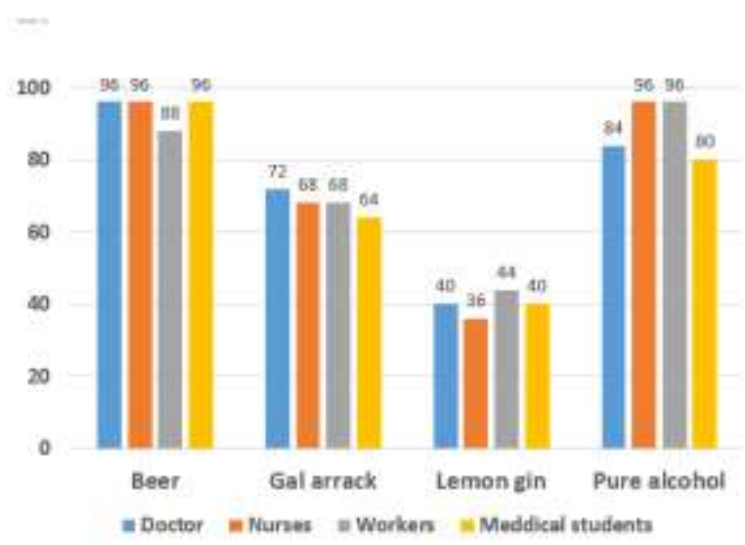

Figure 02: Comparison of detection of the smell of alcoholic samples by all the participants

According to Table 01 and Fig. 02, the detection of the liquor smell of Beer showed more than $80 \%$ accuracy in all the groups. The detection of pure alcohol was also higher among all the health personnel; nurses $96 \%(n=24)$, workers $96 \%(n=24)$, doctors $84 \%$ $(\mathrm{n}=21)$ and students $80 \%(\mathrm{n}=20)$.

There were 3 liquors in this study; Beer, Gal arrack and Lemon Gin. According to Table 01 and Fig. 02, the correct detection of samples were more than $50 \%$ in beer $(94 \%)$ and Gal arrack (68\%). However, the detection of Lemon Gin was less than 50\% among all the participants (doctors 40\%, nurses 36\% and workers $44 \%$ and students $40 \%$ ). Lemon Gin had the highest alcohol concentration (39\%). However, irrespective of the high concentration of alcohol, the detection rate of Lemon Gin was low (less than 44\%). There were four non-alcoholic samples; garlic, ginger, lemon and water. Garlic smell was detected correctly by $91 \%(\mathrm{n}=91 \%)$ and wrongly identified as liquor by $05 \%(\mathrm{n}=05)$. Ginger was detected correctly by $81 \%$ and misidentified as liquor by $05 \%(\mathrm{n}=05)$. Lemon was correctly identified by $78 \%$ and wrongly identified as liquor by $05 \%(\mathrm{n}=05)$ including 2 doctors. Water was detected by $84 \%(\mathrm{n}=84)$ and it was wrongly identified by $6 \%$ and $5 \%$ as ginger and lemon consecutively but none detected water as liquor. The comparison of correct detection of non-alcoholic samples is shown in Fig. 03. 


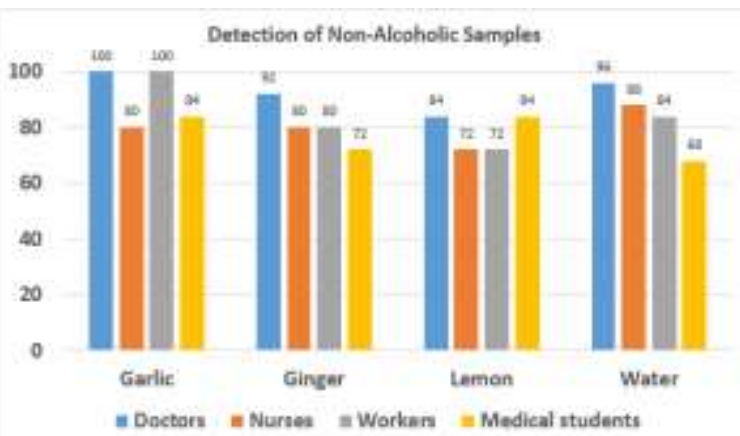

Figure 03: Comparison of the detection of nonalcoholic samples by all the participants.

According to Table 01 and Fig. 03 , more than $70 \%$ of the participants detected non-alcoholic samples correctly.

There were $37 \%(\mathrm{n}=37)$ males and remaining $63 \%$ $(n=63)$ were females. The detection of the smell of liquor compared with sex is shown in Table 02 .

Table 02: Correct detection of smell of liquor according to the sex

\begin{tabular}{lrrr}
\hline Sample & $\begin{array}{r}\text { Male } \\
\mathbf{N = 3 7} \\
\mathbf{n}(\boldsymbol{\%})\end{array}$ & $\begin{array}{r}\text { Female } \\
\mathbf{N}=\mathbf{6 3} \\
\mathbf{n}(\boldsymbol{\%})\end{array}$ & $\begin{array}{r}\text { Total } \\
\mathbf{N = 1 0 0} \\
\mathbf{n}(\boldsymbol{\%})\end{array}$ \\
\hline C (Beer) & $34(92)$ & $60(95)$ & $94(94)$ \\
B (Pure alcohol) & $30(81)$ & $59(93)$ & $89(89)$ \\
E (Gal Arrack) & $26(70)$ & $42(67)$ & $68(68)$ \\
A (Lemon Gin) & $18(49)$ & $22(35)$ & $40(40)$
\end{tabular}

When the detection of the smell of liquor was compared with sex, $92 \%(n=34)$ of males and $95 \%$ $(n=60)$ of females correctly detected liquor smell in beer and there was no statistically significant difference. Regarding Gal arrack, the liquor smell was correctly identified by $70 \%(n=26)$ of males and $67 \%$ $(n=42)$ of females and the difference was not statistically significant $\left(\chi^{2}=0.139, \mathrm{df}=1, \mathrm{p}>0.05\right)$. Regarding Lemon Gin, the liquor smell was correctly identified by $49 \%(n=18)$ of males and $35 \%(n=22)$ of females and the difference was not statistically significant $\left(\chi^{2}=1.830, \mathrm{df}=1, \mathrm{p}>0.05\right)$.

There were $25 \%(n=25)$ doctors and the remaining $75 \%(n=75)$ were non-doctors. Correct detection of liquor by the doctors and others are shown in Table 03 .
Table 03: Correct detection of smell of liquor according to the occupation

\begin{tabular}{lrrr}
\hline Sample & $\begin{array}{r}\text { Doctors } \\
\mathbf{N = \mathbf { 2 5 }} \\
\mathbf{n}(\boldsymbol{\%})\end{array}$ & $\begin{array}{r}\text { Non-doctors } \\
\mathbf{N = 7 5} \\
\mathbf{n}(\boldsymbol{\%})\end{array}$ & $\begin{array}{r}\text { Total } \\
\mathbf{N = 1 0 0} \\
\mathbf{n}(\boldsymbol{\%})\end{array}$ \\
\hline C (Beer) & $24(96)$ & $70(93)$ & $94(94)$ \\
B (Pure alcohol) & $21(84)$ & $68(91)$ & $89(89)$ \\
E (Gal Arrack) & $18(72)$ & $50(67)$ & $68(68)$ \\
A (Lemon Gin) & $10(40)$ & $30(40)$ & $40(40)$ \\
& & & \\
\hline
\end{tabular}

When the detection of the smell of liquor was compared with the occupation, $96 \%(\mathrm{n}=24)$ of doctors and $93 \%(n=70)$ of non-doctors correctly detected liquor smell in beer and according to the Fisher's exact test, the difference was not statistically significant $(\mathrm{p}>0.05)$. Regarding Gal arrack, the liquor smell was correctly identified by $72 \%(n=18)$ of doctors and $67 \%$ $(n=50)$ of non-doctors and the difference was not statistically significant. $\left(\chi^{2}=0.245, \mathrm{df}=1, \mathrm{p}>0.05\right)$. Regarding Lemon Gin, the liquor smell was correctly identified by $40 \%(n=10)$ of doctors and $40 \%(n=30)$ of non-doctors and the difference was not statistically significant $\left(\chi^{2}=0.000, \mathrm{df}=1, \mathrm{p}>0.05\right)$.

According to the age, there were $84 \%(n=84)$ less than 50 years of age and the remaining $16 \%(n=16)$ were more than 50 years of age. The detection of the smell of liquor compared with age groups is shown in Table 04.

Table 04: Correct detection of smell of liquor according to age groups

\begin{tabular}{lrrr}
\hline Sample & $<\mathbf{5 0}$ yrs & $>\mathbf{5 0}$ yrs & Total \\
$\mathbf{N = ~ 8 4}$ & $\mathbf{N = 1 6}$ & $\begin{array}{r}\mathbf{N}=\mathbf{1 0 0} \\
\mathbf{n}(\boldsymbol{\%})\end{array}$ \\
\hline C (Beer) $(\boldsymbol{\%})$ & $\mathbf{n}(\boldsymbol{\%})$ & $94(94)$ \\
B (Pure alcohol) & $74(88)$ & $15(94)$ & $89(89)$ \\
E (Gal Arrack) & $59(70)$ & $09(56)$ & $68(68)$ \\
A (Lemon Gin) & $30(36)$ & $10(63)$ & $40(40)$ \\
& & & \\
\hline
\end{tabular}

When the detection of smell of liquor was compared with the age groups $94 \%(n=79)$ of less than 50 years of age and $94 \%(n=15)$ of more than 50 years of age correctly detected liquor smell of beer and according to Fisher's exact test, the difference was not statistically significant $(\mathrm{p}>0.05)$. Regarding Gal arrack, the liquor smell was correctly identified by $70 \%(\mathrm{n}=59)$ of $<50$-year-old participants and $56 \%$ $(n=09)$ of $>50$-year-old and the difference was not statistically significant $\left(\chi^{2}=1.272, \mathrm{df}=1, \mathrm{p}>0.05\right)$. However, regarding Lemon Gin, the liquor smell was correctly identified by $36 \%(n=30)$ of $<50$ years of age and $63 \%(n=10)$ of $>50$-year-old participants and the difference was statistically significant $\left(\chi^{2}=4.018\right.$, $\mathrm{df}=1, \mathrm{p}=0.045<0.05$ ). 


\section{Discussion}

Pure alcohols are odour-less, colourless and tasteless. Alcohol is a volatile, flammable, colourless liquid with a slight characteristic spirituous odour and a burning taste, and gives an irritant feeling. ${ }^{[3]}$ In this study, 96\% of nurses and minor employees, $84 \%$ of doctors and $80 \%$ of medical students detected the smell of pure alcohol $(95 \%$ alcohol). This may be due to the familiarity of pure alcohols such as surgical spirit among all health personnel. Therefore, in this study, familiarity with the smell of pure alcohols such as surgical spirits among health professionals may have influenced the higher detection of pure alcohol.

Table 01 and Fig. 02 show the pattern of the detection of the liquor smell of beer, gal arrack and Lemon Gin samples by all the groups. The smell of liquor of beer, gal arrack and Lemon Gin is not due to alcohol but due to the additives and congeners. The additives are responsible for taste and smell of liquor and for increasing the product shelf-life. ${ }^{[5]}$ The commonly used alcohol additives are colourants, flavours, emulsifying and stabilizing agents, and antifoaming agents. The congeners are also responsible for the taste and smell of liquor and are the substances which are produced other than the desired type of alcohol during fermentation. They include; methanol, acetone, acetaldehyde, esters, tannins, and aldehydes. ${ }^{[4]}$ In forensic toxicology, the alcohol congener analysis is done to identify the specific alcohol beverage. In this study, according to Table 01 and Fig. 02 the pattern of the detection of the liquor smell of beer, gal arrack and Lemon Gin samples by all the groups showed not much of a difference.

According to Table 01 and Fig. 02, when the detection of liquor smell of the beer is considered, irrespective of the low concentrations $(4.8 \%)$, beer showed the highest detection rate (more than 84\%). However, Lemon Gin, the sample with the highest concentration of alcohol $(39 \%)$ showed the lowest detection rate (less than 44\%). This may be due to the popularity and common usage of beer than Lemon Gin in the community. In the late $1980 \mathrm{~s}$, the incidence of alcoholism among males over 25 years of age in the suburbs of Colombo was $29 \%{ }^{[6]}$ The per capita consumption of alcohol in Sri Lanka has been increasing over the years and 50.3 million $\mathrm{L}$ in 2000 increased to 67.1 million L by $2006 .{ }^{[7]}$ In a study performed by de Silva in 2014, of 238 married males in the Divisional Secretariat area of Wattala, the prevalence of hazardous drinking had been $31 \%$ and that of alcohol use disorders had been $25 \%{ }^{[8]}$ Therefore, consumption of alcoholic beverages is common and popular in the Sri Lankan community.
The higher popularity of beer may be due to the low price (Rs. $180 /=$ a bottle) and less impairment/drunkenness following ingestion.

The ability to detect the smell of liquor is not only important for JMOs but also for other health personnel especially working at accident or emergency services. According to Table 01 and Fig. 02, the doctors, nurses and minor employees showed almost the same pattern of detection rates of liquor smell. Further, in this study, there were $25 \%(\mathrm{n}=25)$ doctors and $75 \%(\mathrm{n}=75)$ nondoctors and when the detection of smells of all the liquors compared with occupation groups, showed no statistically significant difference $(\mathrm{p}>0.05)$. This is a very important factor because nurses also have to keep notes on the patients' behaviour in the BHT. Further, minor employees work as chaperones for the medical officers and this ability would be very helpful, because, medical officers always examine patients with a chaperone by the side, and their views are also important to detect the smell of liquor. Further, not only JMOs, but the other clinicians also have to document their observations on the smell of liquor or under influence of alcohol (UIA) in the Bedhead ticket (BHT) and it is a piece of important evidence in the clinical and autopsy investigations such as road traffic offences, criminal offences and obtaining compensations or insurance.

In Sri Lanka, clinical and autopsy investigations relevant to alcohol intoxication are conducted by both male and female health personnel. People believe that females may not be able to detect the smell of liquor as good as males. However in this study, there were $37 \%$ males and $63 \%$ females and when the detection of the smell of all the liquors was compared with sex, showed no statistically significant difference between males and females $(\mathrm{p}>0.05)$.

The health personnel belonged to different age groups spanning from 20 to 60 years and in this study, there were $84 \%(n=84)$ less than 50 years of age and $16 \%$ $(n=16)$ of more than 50-year-old group. When the detection of the smell of liquor of beer and gal arrack assessed against the age groups, there was no statistically significant difference $(\mathrm{p}>0.05)$. However, regarding the detection of the smell of Lemon Gin showed a statistically significant difference between age groups $\left(\chi^{2}=4.018, \mathrm{df}=1, \mathrm{p}=0.045<0.05\right)$.

Identification rates were high in the substances with familiar smells such as garlic, ginger and beer. According to Table 01, Fig. 02 and 03, the detection of the smells of non-alcoholic samples such as lemon, ginger, and garlic was very high (more than $72 \%$ ) and may be due to day to day familiarity of those smells by 
all the health personnel. However, the water showed a comparatively lower level, most probably due to its odourlessness.

Now, alcohol beverages are produced by adding nonalcoholic substances such as lemon, ginger and garlic. According to Table 01 and Fig. 02, the ability to detect the smell of liquor in Lemon Gin has been drastically reduced in all the health personnel. This is one of the most important observations in this study. For example, irrespective of the highest alcohol concentration $(39 \%)$ of the Lemon Gin, the detection rate was less than $45 \%$ among all the participants. Therefore, the addition of additives with peculiar smells such as lemon may lead to high rate of failure in the detection of the smell of liquor and $30 \%$ and $22 \%$ had false negatively identified it as lemon and perfume consecutively. Therefore, the lower detection rate of Lemon Gin may be due to the masking effect of the added lemon flavour to the alcohol beverage.

Further, each non-alcoholic sample (lemon, ginger and garlic) was wrongly detected as liquor by $5 \%$ of participants (false positive diagnosis). However, doctors did not wrongly diagnose the non-alcoholic samples as liquor except by 2 doctors with lemon (false positive diagnosis).

The wrong assessment of the smelling of liquor can cause serious consequences not only for medico-legal service but also for many other parties. In the medicolegal practice, the medical officers come across many alcoholic beverages with different additives such as lemon, garlic or ginger that can mask the original smell of liquor and lead to a false positive or false negative diagnosis. Further, detection of the smell of liquor as a legal fact is especially dangerous because the results are not objective and cannot be reproduced. Moreover, an even single mistake may cause serious consequences and injustice to victims, accused, legal authorities and to the medical officers. Further, the medical officer concerned might lose registration for wrongly interpreting the smell of liquor. However, this study highlighted the possibility of making such mistakes by any health personnel including medical officers with the justification of those depending on their familiarity and the masking effect of additives and congeners. Moreover, the medical officers have not been given a special undergraduate or postgraduate training on the detection of the smell of liquor.

Therefore, detection of smell of liquor should be used only as a very basic screening method and then should be confirmed with a more scientific and objective method such as breath analyser or detection of alcohol in blood, urine, saliva or sweat. In the UK, forensic physicians do not perform clinical examinations to diagnose under the influence of alcohol. When a person is suspected of under influence of alcohol in the community, police performs Breathalyzer as a screening method and followed by intoxication meter analysis, and if indicated blood tests are performed. ${ }^{[6,}$

${ }^{9]}$ When a person is suspected as under the influence of alcohol within a UK hospital, the doctor takes a blood or urine sample for analysis. Therefore, similar to the findings of this study, the UK has identified the inherent problems of liquor smell and the clinical examination for alcohol or drug-induced impairment assessment.

In alcohol metabolism, $95 \%$ of alcohol will remain in the blood and it is better to target this 95\% and arrange alternative methods to identify the under influence of alcohol. There are many non-invasive reliable methods to assess the level of alcohol in the blood such as Breathalyzer, urine or, sweat or saliva chemical strips. ${ }^{[10]}$ These objective methods are accurate and reliable than the subjective non-reliable methods such as smelling of liquor or clinical impairment assessment examinations.

\section{Conclusions}

The ability to detect smells of liquor by the nurses is important to make accurate nurse's notes in the BHT. The ability to detect smells of liquor by the "workers" is also important for the medical officers when they work as chaperones in the clinical examinations.

The detection of the smell of liquor is affected by the familiarity and the masking effects of the additives and congeners. Therefore, medical officers tend to miss the diagnosis of liquor smell in the medico-legal investigations. Wrong or misdiagnosis may lead to serious professional consequences, and in the absence of special undergraduate or postgraduate tanning on the detection of smelling of liquor, these professional consequences could not be justified. Moreover, the smell of liquor is a subjective assessment and the findings cannot be reproduced.

Therefore, we need to reconsider the using of liquor smell in the medico-legal investigations and should be considered as a basic screening method and for confirmation, we recommend to introduce objective, reproducible, scientific methods such as blood alcohol analysis or non-invasive urine, saliva or sweat analysis. Our data may help to convince and/or reinforce medico-legal policymakers to adopt a positive change. 


\section{Acknowledgements}

We would like to acknowledge the participants; the Medical staff, non-medical staff and medical undergraduates for the participation.

\section{Conflict of interests}

Financial and non-financial: None

\section{Declaration}

The authors declare that this research paper was not published or not under consideration in part or as a whole in any other journal or a proceeding.

\section{References}

1. Dayaratne CD, State of Sri Lankan alcohol industry and analysis of governing policies, research, Studies working paper series; No.19; Institute of policy studies Sri Lanka. 2013. pp-3

2. Motor Traffic Act-section-151; Socialist Republic of Sri Lanka. https://www.lawnet.gov.lk/1946/ 12/31/motor-traffic -amendment-5/(2019.02.20)

3. Reddy KSN. The essentials of forensic medicine and toxicology. $15^{\text {th }}$ Ed. India: Jaypee brothers; 1995. p-454.

4. Rohsenow DJ, Howland J, Arnedt JT, Almeida $\mathrm{AB}$, Greece J, Minsky S, Kempler CS, Sales S. Intoxication with bourbon versus vodka: effects on hangover, sleep, and next-day neurocognitive performance in young adults. Alcoholism: Clinical and Experimental Research. 2010; 34 (3): $\quad 509-18 . \quad$ Doi: $\quad 10.1111 / j .1530-$ 0277.2009.01116.x

5. Commissioner General of Excise. Administrative Report. Colombo (Sri Lanka): 2006. http://www.excise.gov.lk/web/index. (2019.02.20)

6. Somatunga LC, Ratnayake LVR, Wijesinghe WMDNK, Yapa YMMM, Cooray MPNS. National alcohol use prevalence survey in Sri Lanka. Journal of the Postgraduate Institute of Medicine 2014;1(1):E7:1-12. Doi: http://dx.doi. org//jpgim. 7858

7. Samarasinghe D, Dissanayake SAW, Wijesinghe CP. Alcoholism in Sri Lanka: an epidemiological survey. British Journal of Addiction. 1987; 82(10):1149-53. PMID: 3479164

8. Commissioner General of Excise. Administrative Report. Colombo (Sri Lanka): 2006. http://www.excise.gov.lk

/web/index. (2019.01.22).

9. Penttilä A, Karhunen PJ, Pikkarainen J. Alcohol screening with the Alcoscan test strip in forensic praxis. Forensic Sci Int. 1990 Jan; 44(1): 43-8. PMID: 2303207

10. Ashdown HF, Fleming S, Spencer EA, Thompson MJ, Stevens RJ. Diagnostic accuracy study of three alcohol breathalysers marketed for sale to the public. BMJ Open. 2014 Dec 19;4(12):e005811. Doi: 10.1136/bmjopen-2014005811 .

\section{Annexure 01: Part of a filled questionnaire}

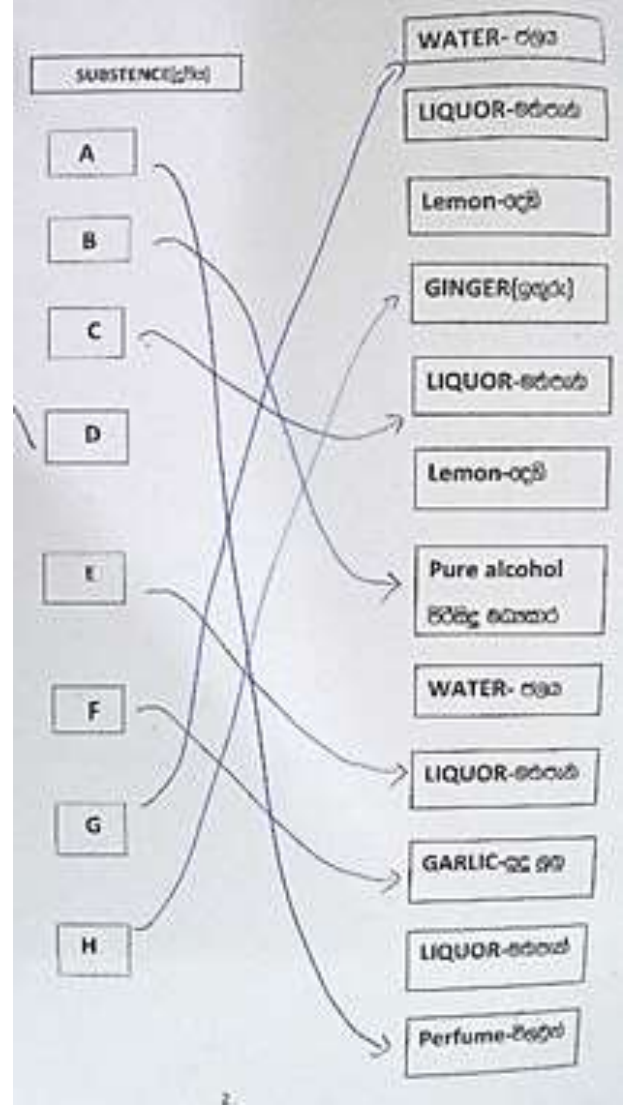

